\title{
EFFICIENCY OF COMMUNICATION IN PERCEIVING ONLINE LEARNING
}

\author{
Maria-Lucia RUSU, Ioan VIRCA, Ioan-Dan POPA \\ "Nicolae Bălcescu" Land Forces Academy, Sibiu, Romania \\ rusu.maria@armyacademy.ro, virca.ioan@armyacademy.ro,paragon1971@gmail.com
}

\begin{abstract}
Online learning in the pandemic took place as an emergency situation in which the quality and comfort of life were affected by loneliness, social distancing, risks, stress, fear, anxiety and automatically by a negative perception of the virtual environment. The Romanian education system has become aware of the need to resize the education process and a large number of students have gained knowledge through new online learning methods, which have prompted teachers to redesign their courses and teaching strategies to improve learning effectiveness. The article presents the general characteristics of online learning, which serve distance learning in this time of pandemic crisis. The research is applied to university education and highlights the advantages, challenges and limitations of online learning. The ultimate goal of the research is to identify the perception of participants in this type of virtual education and their participatory guidance through effective communication.
\end{abstract}

Keywords: online learning, interactive online education, efficient communication, feedback, coping

\section{Introduction}

Contemporary society has been exposed to new challenges by the COVID-19 pandemic, which has brought many changes and re-approaches to the ways of human interaction. It was the online environment that provided the right framework for many human activities. The new reality of the educational environment was reconfigured, and teachers and students were forced to participate in online courses. For young people, technology and the virtual world are attractive, but for teachers there must be a strong motivation to use online platforms effectively for online learning.

The Romanian education system faces methodological and technical problems in ensuring the optimal conditions for online activity. But the university environment benefits from a number of advantages in implementing this educational format compared to the pre-university environment. These advantages consist in the age of the beneficiaries, their level of independence and the high digital skills they possess. At the level of universities, technical support groups have been created that have created online e-learning platforms for carrying out activities in the virtual environment and have provided digital assistance. IT experts have developed audio-video tutorials with instructions for using the software and have imposed internal regulations that structure the activity of users.

Online learning is an activity supported by the use of information and communication technology, in order to provide permanent information content, through different ways of presentation, with visual and sound elements for a more attractive and interactive learning. Digital technologies 
have been the logistical basis and infrastructure of connectivity, facilitating the development of educational activities online. In this context, the essential elements to facilitate learning are the instructive-educational, technical and social process [1]. But, of course, a qualitative management in the institutional development of universities, didactic design and the involvement of the human factor are elements that determine the efficiency and success of online programs. The main pawn is the teacher, who plays several roles: pedagogue, instructor, designer and facilitator. The teacher is defined by the ability to organize his/her instructiveeducational activity, to inform, to lead the didactic process, by a technical aptitude and to create experimental applications. The teacher of the current reality is receptive to the new, creative, rejects the routine and the pattern. The teacher is the active moderator of the course, provides informational content and the opportunity to study, monitors activities and provides support and even technical assistance [2]. The readiness of the teacher keeps active the communication with the students in an online context, when he/she dialogues during the online courses, responds to their e-mails, evaluates the tasks performed by them and provides them with information and announcements about the courses.

\section{Research Methodology}

The elaborated scientific research integrates a set of theoretical and empirical research methods in order to facilitate the understanding of the research objectives and the interpretation of the effects. Based on the literature, we analyzed the role of effective communication in obtaining results from online learning. The research is applied to university education and highlights the advantages, challenges and limitations of online learning. The ultimate goal of the research is to identify the perception of participants in this type of virtual education and their participatory guidance through effective communication. The chosen study topic is topical and refers to a current problem facing Romanian education.

\section{Perception of online learning}

There are various factors that influence the perception of online learning, such as: online resources, the environment in which students work, positive or negative emotions, anxiety, coping behaviors and stressors. All these factors must be taken into account by the teacher when designing their course. The term stress is more and more often present in this pandemic period in the individual vocabulary, it is always correlated with terms such as: difficulty, adversity and suffering, which exert pressure and dysfunction on the person. Therefore, those involved in the educational process expressed their anxiety and stress as an emergency reaction, generated by the adaptation to the new reality imposed by the pandemic. This path went through the alarming phase, characterized by nervousness and confusion, then they manifested a phase of resistance, in which they mobilized their resources, but also a phase of exhaustion in which entropic effects accumulated, eliminating balance. The response that each person gives to stress is the result of assessing the situations generated by stress. This mechanism is known as coping and includes all the cognitive and behavioral efforts mobilized in order to manage the tensions to which the person is exposed [3], [4].

Behaviorally and communicatively, students' responses to stress during the pandemic period were manifested by decreased performance, deterioration of interpersonal relationships, lack of desire for communication and dialogue, sleep disorders, absenteeism and even aggressive behaviors. In students, coping should be perceived as an active process by which they overcome stressful situations and manage to master them based on assessments and selfassessment of their abilities. Coping must 
be mediated by the teacher through the ability to control by efficient and permanent evaluation and communication. As for the dynamics of communication, it is oriented on coping focused on the problem and emotion. The teacher strives to manage and reduce stress-inducing problems in online courses, by providing logical and useful information, a clear, concrete and specific design of the virtual environment in which the courses are presented, setting clear objectives, using explanation and logical argumentation, allocation of time and continuous evaluation.

The feedback dialogue aims at the continuous evaluation of the informational and emotional flow in the online environment. Emotion-centered coping presents the cognitive and behavioral efforts manifested by the teacher to diminish and change the student's discomfort created by stress. In this sense, the teacher has at hand dialogue, imagination, feedback and interaction. In the educational relationship it is indicated that the teacher provides the positive stimuli that the student needs, for a positive perception of online learning.

Students' personalities influence their attitude and perception towards online learning [5]. Extroverted and sociable students perceived online learning with anxiety and they were not happy with it because they were alone in front of a monitor. They prefer a traditional face-to-face approach. In contrast, introverted, solitary, and reflective students perceived the online learning approach better because they were not so exposed to interaction and teamwork.

An important role in the perception of students and teachers on online learning is played by conscientiousness and acceptability to new experiences. Participants with high awareness and involvement approached the online learning positively and obtained learning outcomes. The pandemic crisis forced the participants in the educational act to accept and like the virtual world. And those who have a predictability towards new and innovation have made this transition to the online environment easier. Students, unlike some teachers, looked optimistic about the new experience and showed positive attitudes towards technology-assisted learning. The correlation between personality, communication, conscientiousness and acceptability offers satisfaction and results in online learning.

Consequently, if students' perception and enjoyment is positive, the effectiveness of online learning would improve. Online learning could be successful if the individual needs and preferences of students were met through courses and interactive methods in online contexts. Teachers need to use tailored teaching strategies and approaches in design to maximize learning outcomes. It is recommended to design innovative content that, through pedagogical dialogue, would release negative and anxious emotions and reduce the stress of introverted students. And for the extroverts, the courses must offer them opportunities for interpersonal communication and the implementation of online work groups. The whole activity should be oriented towards a new experience in which innovation and the amount of information accumulated grows, using current technologies.

\section{The advantages of online learning}

The benefits of online learning have included distance learning, accessibility, safety and comfort. In the case of e-learning platforms, information is continuously available, students can access the information when they have time.

They have materials from courses and seminars at hand and can even chat with the teacher. Content can be easily updated, corrected or deleted, but especially distributed in real time. Access to e-learning platforms is facilitated simultaneously so that users can simultaneously access computer content. And in terms of course content, it is designed and delivered to students in a much clearer form, perceptible for more effective learning. 
Online learning benefits students in creating a new virtual community, in which they manage to engage in collaborative learning activities through communication and collaboration. Thus, students are actively involved and determined to process and synthesize information and concepts, not just to memorize.

The development of today's society allows the favorable framework for online education where the high turnover of information content and its rapid transfer, technological development and communication revolution are observed. The expansion and use of this educational opportunity can open new horizons for universities towards modernization, digitization and an increasing absorption of students (using alternatively online, traditional or hybrid education).

\section{Limits and difficulties of online learning}

Online platforms where virtual study classes take place have limitations and disadvantages in terms of high infrastructure cost, academic integrity and intellectual property in respecting copyright when exchanging information, sometimes limiting the upload of media files and reducing operating efficiency of the platform when a large number of users are connected simultaneously. There are difficulties in using the technology, which is why there are often problems using and accessing information or carrying out tasks or projects. There are situations of confusion and disorientation causing a lack of motivation. But with the help of the students, video tutorials are made.

Also, the stage of designing and organizing the contents of virtual teaching consumes more time than the time allocated in traditional teaching.

In the online environment, students have a low involvement, which constantly requires stimuli or control elements in communication. Online learning was limited to inefficiency and difficulties in supervising students during courses but especially at exams [6].

The challenges of the online environment appear in distance learning when the home environment must be transformed into something organized, planned and monitored by an authority through a computer screen. The longing for the ethos of the university, of the space in the classroom, of the whole friendly atmosphere that creates the study mood. Belonging to a group, the relevance of connecting with others and seeing the reactions in the eyes of the others is a difficult exercise in the online environment. Extracurricular activities are missing, which take place in a non-formal setting, since the online generally standardizes and flattens the activity. But the imagination and spontaneity of the teachers managed to animate this virtual space through all kinds of interactive activities and non-formal elements. Regarding health, online learning requires excessive use of one's eyes and participants may suffer from eye disorders [7].

\section{Interactive online education}

The challenges and disadvantages of online learning can be reduced or mitigated through interactive educational methods, namely: feedback and interaction, so participants in virtual courses can yield new experience and achieve effective results from online learning. It is true that in the virtual environment it is much harder for the teacher to connect beyond words / screen with the students.

Interactive teaching means didactic interventions addressed by the teacher to the class or subgroup [8]. Interaction in online learning is achieved with methods of developing empathy by connecting the teacher and students through video conferencing, with the ability to see, dialogue and exchange computer files. The teacher presents in an attractive form the educational content and determines the students to intervene, engages them in 
dialogue, in this interactive channel.

Teaching systems work through selfregulation, i.e. through feedback. The purpose of feedback is to regulate teaching-learning based on assessment that shows whether or not educational goals have been achieved. It turns out that the teacher must be permanently concerned with this principle in view of improving their own courses but also training students in self-assessment of activities, because they themselves can appreciate, correct and improve. Feedback is an important and necessary element in the instructive-educational process, it has the value of control and regulation in online learning [9]. Educational communication becomes effective through feedback, it increases the satisfaction of teachers and students. The purpose of interactive education is to help the teacher and students to collaborate effectively online, to make the teaching process faster, to update the teaching strategies and to improve the students' performances. E-learning platforms should offer a wider range of digital features to enable a collaborative environment by expressing communication and interaction between students [10].

The online experience will allow students to have an active role as an explorer and future scientific researcher. He will practice virtual browsing skills for accessing databases of scientific research materials. Thus, curiosity and collaboration with a coordinator will guide them to new scientific experiences, through which they will improve themselves.

\section{Conclusion}

The option of doing online education in the pandemic came as a rescue and a substitute for traditional education. Online training has an instructive dimension of information transmission and is better folded on segments of users who have already trained skills in the traditional training system. It is difficult for e-learning platforms to replace or create what implies a pedagogical relationship between teacher and disciple (creativity, empathy, reactivity, spontaneity and emotion).

The entire experience of the current pandemic crisis must be converted and capitalized on an opportunity to calibrate education as a system and process, in a dynamic of development and innovation of society. The education system has the capacity to adapt flexibly to evolution and even to assume certain vulnerabilities, and to be able to find alternatives in crisis situations. It is necessary to rethink the curriculum and courses' syllabus for virtual content and train teachers with skills in planning, organizing and teaching online. Students' satisfaction with online education depends on: the quality and clarity of the design of the informative content, the interaction with the teacher, the active communication with the other participants [11]. Differences in perception and satisfaction alternate due to several aspects: online resources, the environment in which students work, emotions, anxiety, coping behaviors, stressors, age and year of study of the student, low interest in engaging in online activities, especially if the field of study requires face-to-face learning (e.g. in the medical field) [12], the ability to browse online platforms and manage one's time. Students' perception is that in the online environment they receive fewer tasks than during traditional courses, and flexibility and presence are greater online. Instead, teachers argue that organizing and planning content for online courses requires more time and effort. Students are satisfied with the quality of online teaching and the technical skills offered by teachers. However, students and teachers opt for traditional classes with physical presence in the classroom.

In conclusion, professionals need to address educational strategies that integrate interactive online methods and effective and continuous communication in the online learning process, so that students achieve consistent and sustainable learning outcomes. The dialectics of online knowledge can be mediated through communication and interactive education. 


\section{References List}

[1] Lee, S.L., Srinivasan, S., Trail, T., Lewis, D. \& Lopez, S. (2011). Examining the relationship among student perception of support, course satisfaction, and learning outcomes in online learning. The Internet and Higher Education, 14(3), pp. 158163, https://doi.org/10.1016/j.iheduc.2011.04.001

[2] Martin, F., Wang, C. \& Sadaf, A. (2018). Student perception of helpfulness of facilitation strategies that enhance instructor presence, connectedness, engagement and learning in online courses. The Internet and Higher Education, 37, pp. 52-65 https://doi.org/10.1016/j.iheduc.2018.01.003

[3] Lazarus, R.S., \& Folkman, S. (1984). Stress, appraisal and coping. New York: Springer.

[4] Endler, N.S., \& Parker, J.D.A. (1990). Multidimensional Assessment of Coping: A Critical Evaluation. Journal of Personality and Social Psychology, 58(5), 844-854.

[5] Keller, H. and Karau, S.J. (2013). The importance of personality in students' perceptions of the online learning experience. Computers in Human Behavior, 29 (6), 2494-2500. https://doi.org/10.1016/j.chb.2013.06.007

[6] Mukhtar, K., Javed, K., Arooj, M. \& Sethi, A. (2020). Advantages, Limitations and Recommendations for online learning during COVID-19 pandemic era Online learning during COVID-19 pandemic era. Pakistan Journal of Medical Sciences, Vol.36 (4), S27S31. https://doi.org/10.12669/pjms.36.COVID19-S4.2785

[7] Mohan, A., Sen, P., Shah, C., Jain, E. \& Jain, S. (2021). Prevalence and risk factor assessment of digital eye strain among children using online e-learning during the COVID-19 pandemic. Digital eye strain among kids (DESK study-1). Indian Journal of Ophthalmology, 69 (1), 140-144. https://doi.org/10.4103/ijo.IJO_2535_20

[8] Raviolo, P. (2019). Online higher education teaching practices. Proceedings of the 10th International Conference on E-Education, E-Business, E-Management and E-Learning. 2019, Association for Computing Machinery: Tokyo, Japan. p. 79-84. https://doi.org/10.1145/3306500.3306548

[9] Perraton, H. (1988). A theory for distance education. In Distance education: International perspectives, ed. D. Sewart, D. Keegan, and B. Holmberg, 34-45. New York: Routledge.

[10] Ayuyang Richard R. (2019). Interactive Learning (iLEARN) Tool: An eLearning Portal Designed Using MOODLE for Cagayan State University in the Philippines. ICCAI '19: Proceedings of the 2019 5th International Conference on Computing and Artificial Intelligence, pp. 11-16. https://doi.org/10.1145/3330482.3330507

[11] Swan, K., Shea, P., Fredericksen, E., Pickett, A., Pelz, W. \& Maher, G. (2000). Building knowledge building communities: consistency, contact and communication in the virtual classroom. Journal of educational Computing Research, 23, pp. 389-413.

[12] Mohd, S., Abu, M., Aziah, I. (2012). Learning Styles and Perception of Engineering Students Towards Online Learning. Procedia - Social and Behavioral Sciences, Vol. 69, pp. 669-674, https://doi.org/10.1016/j.sbspro.2012.11.459 